\title{
Intrathecal Ziconotide and Morphine for Pain Relief: A Case Series of Eight Patients with Refractory Cancer Pain, Including Five Cases of Neuropathic Pain
}

\author{
Ana Bella de la Calle Gil · Isaac Peña Vergara • María Auxiliadora Cormane \\ Bornacelly · Antonio Pajuelo Gallego
}

To view enhanced content go to www.neurologytherapy-open.com Received: September 16, 2015 / Published online: November 12, 2015

(C) The Author(s) 2015. This article is published with open access at Springerlink.com

\section{ABSTRACT}

Introduction: Studies have shown that, at low doses and with careful titration, combination therapy with intrathecal ziconotide and morphine results in rapid control of opioid-refractory cancer pain. However, there is a lack of published data regarding the efficacy and safety of intrathecal ziconotide specifically for the treatment of neuropathic cancer pain.

Case series: Case reports of ziconotide intrathecal infusion in eight patients (age 45-71 years; $75 \%$ male) with chronic, uncontrolled cancer pain during therapy with intrathecal morphine plus bupivacaine were reviewed. Neuropathic pain was confirmed in five patients. Treatment was initiated with adjunctive ziconotide when pain $\geq 5$ on a visual analog scale persisted in spite of 3 successive $20 \%$ dose increases of intrathecal

Electronic supplementary material The online version of this article (doi:10.1007/s40120-015-0035-z) contains supplementary material, which is available to authorized users.

A. B. de la Calle Gil · I. Peña Vergara .

M. A. Cormane Bornacelly · A. Pajuelo Gallego ( $\square)$

Hospital Universitario Virgen del Rocío, Seville,

Spain

e-mail: apajuelog@gmail.com morphine. Ziconotide was initiated at $0.5-1.0 \mu \mathrm{g} /$ day, with mean increases of $0.5 \mu \mathrm{g}$ every 4-7 days if required (maximum dose $10 \mu \mathrm{g} /$ day; mean dose $4.9 \mu \mathrm{g} /$ day). Pain intensity was reduced in all patients after 3-5 days. Of the eight patients, three died for reasons unrelated to ziconotide, three discontinued treatment due to adverse effects (predominantly psychoneurological disorders), and one patient is still receiving treatment. One patient discontinued ziconotide due to confusion and delirium. Due to continued lack of pain control with intrathecal morphine, intrathecal fentanyl was initiated; however, effective pain relief was not achieved with $1500 \mu \mathrm{g} /$ day. Ziconotide was restarted and the patient then achieved pain control.

Conclusion: On the basis of our clinical experience, we recommend adding ziconotide to intrathecal opioid-based therapy in cancer patients with neuropathic pain inadequately controlled by intrathecal morphine alone.

Funding: Eisai, Spain.

Keywords: Cancer pain; Case series; Intrathecal; Morphine; Neuropathic cancer pain; Ziconotide 


\section{INTRODUCTION}

Cancer pain is a major health problem, affecting up to $30 \%$ of patients with early-stage cancer, and $65-85 \%$ of patients with advanced disease [1-4]. Furthermore, at least one-third of patients with cancer pain classify it as moderate or severe $[3,5]$ and many patients do not receive adequate pain management [6].

The neurophysiology of cancer pain is complex and includes inflammatory, neuropathic, ischemic, and compressive mechanisms [7]. Pain in patients with cancer can be caused directly by the cancer or can be due to treatment or associated comorbidities. Correctly identifying the underlying cause of the pain will likely to lead to more appropriate pain management strategies $[8,9]$. This is particularly important for neuropathic cancer pain, which is more likely to be caused by treatment or comorbid disease, and is more difficult to treat than nociceptive cancer pain $[8,9]$.

Compared with the general population, neuropathic pain has been studied in much less detail in patients with cancer [9]. The prevalence of neuropathic pain in patients with cancer varies from $19 \%$ to $39.1 \%$, depending on whether or not patients with mixed pain as well as pure neuropathic pain are included in the definition [8]. Neuropathic cancer pain is under-reported, under-diagnosed, and under-treated, and other treatment strategies are needed in addition to opioid analgesia for optimal pain management $[8,9]$. Furthermore, the intrathecal administration of drugs should be considered in patients with chronic moderate-to-severe pain when other less-invasive therapies fail or if they produce intolerable adverse events [10-12]. The intrathecally administered non-opioid analgesic ziconotide, a conopeptide that acts by selectively blocking $\mathrm{N}$-type calcium channels, is approved in the United States in patients with severe chronic pain that is refractory to other treatments [13], and in Europe in patients with severe chronic pain requiring intrathecal analgesia for pain control [14]. Ziconotide can be used in combination with other intrathecal drugs, and there are studies that suggest that it has an additive analgesic effect with opioids, with minimal risk of developing dependence or tolerance [15-23].

The 2012 Polyanalgesic Consensus Conference (PACC) polyanalgesic algorithm for intrathecal drug delivery in the management of pain recommends ziconotide as first-line intrathecal treatment options for chronic refractory nociceptive, mixed, or neuropathic pain [10]. Ziconotide is included as a possible drug of choice for opioid combination therapy in second- and third-line treatments [10].

Numerous studies have demonstrated that intrathecal ziconotide reduces the intensity of pain in patients with and without cancer, albeit with a high incidence of adverse effects [15, 17-23]. Recent studies have demonstrated that, at low doses and with careful titration, intrathecal combination therapy with ziconotide and morphine resulted in rapid control of opioid-refractory cancer pain [15, 16]. However, there is a lack of published data regarding the efficacy and safety of intrathecal ziconotide specifically for the treatment of neuropathic cancer pain.

In this report, we present a case series documenting the efficacy and safety of intrathecal ziconotide added to intrathecal morphine in eight patients with opioid-refractory cancer pain, five of whom had confirmed neuropathic pain. 


\section{CASE SERIES}

This retrospective case review included all patients treated with intrathecal ziconotide for neuropathic cancer pain at our pain unit (Hospital Universitario Virgen del Rocío in Seville, Spain) between 2009 and 2012. All procedures followed were in accordance with the ethical standards of the responsible committee on human experimentation (institutional and national) and with the Helsinki Declaration of 1964, as revised in 2013. Informed consent was obtained from all patients included in the study.

At our pain unit, intrathecal ziconotide is administered alone or in combination with other drugs for all patients with moderate-to-severe chronic pain who, regardless of the cause of pain, do not show an adequate response to other treatment regimens, including intrathecal morphine, or who present with significant adverse events to such treatment. Patients with an estimated survival time less than 3 months are eligible to receive a completely implanted internal pump.

For this case series, neuropathic pain was identified using the Spanish translation of the Douleur Neuropathique (DN4) questionnaire [24]. The DN4 questionnaire consists of a total of 10 items:7 items related to the quality of pain (burning, painful cold, electric shocks) and its association with abnormal sensations (tingling, pins and needles, numbness, itching), and three related to neurological examination in the painful area (touch hypoesthesia, pinprick hypoesthesia, tactile allodynia). A score of one was given to each positive item and a score of zero to each negative item. The total score was calculated as the sum of all 10 items, and the cutoff value for the diagnosis of neuropathic pain was a total score of $4 / 10$. A visual analog scale (VAS), which ranged from 0 (no pain) to 10 (worst imaginable pain), was used to assess pain intensity.

Between 2009 and 2012, we treated eight patients with cancer pain using intrathecal ziconotide (Table 1). The patients, aged between 45 and 71 years, were predominantly male $(n=6 ; 75 \%)$ and had uncontrolled pain, at times with an intense neuropathic pain component, during therapy with high doses of intrathecal morphine plus bupivacaine administered in conjunction with oral adjuvant analgesic therapy, such as amitriptyline, duloxetine, gabapentin, and pregabalin. DN4 scores ranged from 2 to 10 . Five patients had a DN4 score $\geq 4$, signifying a diagnosis of neuropathic pain. Baseline VAS scores ranged from 7 to 9 .

Table 1 Baseline demographic and clinical characteristics of the eight patients who received treatment with ziconotide for cancer pain at the Hospital Universitario Virgen del Rocío in Seville, Spain since 2009

\begin{tabular}{|c|c|c|c|c|c|c|c|c|}
\hline \multirow[t]{2}{*}{ Characteristic } & \multicolumn{8}{|c|}{ Patient number } \\
\hline & 1 & 2 & 3 & 4 & 5 & 6 & 7 & 8 \\
\hline $\operatorname{Sex}(M / F)$ & $\mathrm{M}$ & $\mathrm{M}$ & $\mathrm{F}$ & $\mathrm{F}$ & M & M & M & M \\
\hline Age (years) & 45 & 48 & 44 & 58 & 63 & 57 & 59 & 71 \\
\hline Cancer type & Rectal & Sciatic sarcoma & Maxillary & Rectal & Colon & Lung & Prostate & Laryngeal \\
\hline DN4 score & 5 & 10 & 4 & 8 & 4 & 2 & 3 & 3 \\
\hline VAS score & 8 & 9 & 7 & 8 & 8 & 9 & 8 & 8 \\
\hline
\end{tabular}

$D N$ douleur neuropathique, $F$ female, $M$ male, $V A S$ visual analog scale 
Table 2 Intrathecal ziconotide and morphine combination therapy dosing information

\begin{tabular}{|c|c|c|c|c|c|c|c|c|}
\hline \multirow[t]{2}{*}{ Dosing } & \multicolumn{8}{|c|}{ Patient number } \\
\hline & 1 & 2 & 3 & 4 & 5 & 6 & 7 & 8 \\
\hline \multicolumn{9}{|l|}{ Ziconotide dose $(\mu \mathrm{g} /$ day $)$} \\
\hline Initial & 0.5 & 0.5 & 0.5 & 0.6 & 1.0 & 0.5 & 0.5 & 0.5 \\
\hline Final & 10 & 8 & 6 & 6 & 5 & 3.5 & 1 & 1 \\
\hline \multicolumn{9}{|l|}{ Morphine dose (mg/day) } \\
\hline Initial & 12 & 6 & 10 & 8 & 9 & 11 & 12 & 15 \\
\hline Final & 12 & 6 & 10 & 0 & 6 & 11 & 12 & 15 \\
\hline Ziconotide treatment duration (months) & 10 & 8 & 7 & 3.5 & 2 & 2 & 0.5 & 1.2 \\
\hline
\end{tabular}

All patients received a fixed flux intrathecal infusion pump ( $1 \mathrm{~mL} /$ day $)$ with the catheter tip positioned at the T6-T8 level. Treatment was initiated with ziconotide when pain $\geq 5$ on the VAS persisted despite 3 successive $20 \%$ increases in the intrathecal dose of morphine. The five patients with neuropathic pain did not respond to high-dose intrathecal morphine combined with bupivacaine. In all patients, treatment with ziconotide was initiated at $0.5-1.0 \mu \mathrm{g} /$ day (Table 2), with mean increases of $0.5 \mu \mathrm{g}$ every $4-7$ days, depending on pain control. Ziconotide was added to the intrathecal therapy without discontinuing intrathecal morphine. The maximum final dose of intrathecal ziconotide was $10 \mu \mathrm{g} /$ day, with the mean final dose being $4.9 \mu \mathrm{g} /$ day. Duration of treatment ranged from 0.5 to 10 months.

A reduction in pain intensity was noted in all patients 3-5 days after initiating treatment with ziconotide. Compared with VAS scores of 7-9 at baseline, patients had scores ranging from 3 to 6 at the end of treatment (Fig. 1). Of the eight patients who received ziconotide, four died for reasons unrelated to ziconotide treatment, three required discontinuation of treatment due to adverse effects, and one patient is still receiving treatment.

\section{Case 1}

This 45-year-old male patient with metastatic rectal cancer and neuropathic pain (DN4 score of 5) was unresponsive to intrathecal morphine $12 \mathrm{mg} /$ day (VAS score of 8). Intrathecal ziconotide $0.5 \mu \mathrm{g} /$ day was added to therapy in April 2009. The patient was also receiving oral gabapentin $900 \mathrm{mg}$ every $8 \mathrm{~h}$, amitriptyline $25 \mathrm{mg}$ every $24 \mathrm{~h}$, and transdermal fentanyl $200 \mu \mathrm{g}$. Intrathecal ziconotide was administered for 10 months with no adverse events. At his last assessment, the patient was receiving ziconotide $10 \mu \mathrm{g} /$ day plus morphine $12 \mu \mathrm{g} /$ day, and his VAS score was five. The patient died in February 2010.

\section{Case 2}

This 48-year-old male patient had metastatic sciatic sarcoma with neuropathic pain (DN4 score of 10). He was unresponsive to intrathecal morphine $6 \mathrm{mg} /$ day (VAS score of 9). Intrathecal ziconotide $0.5 \mu \mathrm{g} /$ day was added to therapy in May 2009. The patient was also receiving oral pregabalin $200 \mathrm{mg}$ every $12 \mathrm{~h}$, amitriptyline $50 \mathrm{mg}$ every $24 \mathrm{~h}$, and oxycodone/naloxone controlled release 


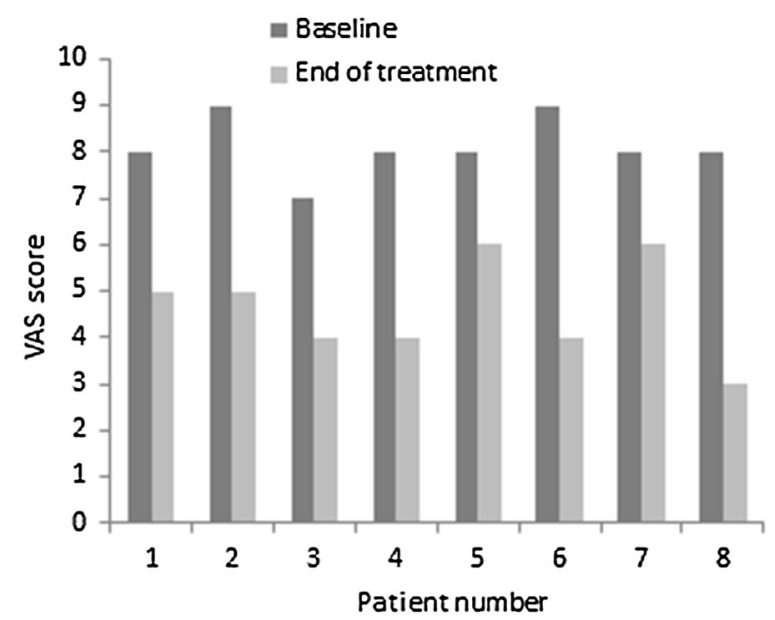

Fig. 1 VAS scores of pain intensity at baseline and at the end of treatment with intrathecal ziconotide. $V A S$ visual analog scale

$60 / 30 \mathrm{mg}$ every $12 \mathrm{~h}$. Ziconotide was administered for 8 months with no adverse events. At the patient's assessment, his ziconotide dose had been titrated to $8 \mu \mathrm{g} /$ day, and his morphine dose remained unchanged at $6 \mathrm{mg} /$ day. The patient's VAS score had improved from 9 at baseline to five at the end of treatment. The patient died in January 2010.

\section{Case 3}

This was a 44-year-old female patient with a large maxillary tumor and neuropathic cancer pain (DN4 score of 4). She was unresponsive to intrathecal morphine $10 \mathrm{mg}$ /day (VAS score of 7). Intrathecal ziconotide $0.5 \mu \mathrm{g} /$ day was added to therapy in June 2009. The patient was also receiving oral gabapentin 900-1200 mg every $8 \mathrm{~h}$, amitriptyline $25 \mathrm{mg}$ every $24 \mathrm{~h}$, and oxycodone/naloxone controlled release $80 / 40 \mathrm{mg}$ every $12 \mathrm{~h}$. Ziconotide was administered for seven months with no reported adverse events. At the last assessment, the ziconotide dose had been increased to $6 \mu \mathrm{g} / \mathrm{day}$, and the morphine dose remained unchanged. The VAS score had improved from
7 at baseline to 4 at the end of treatment. The patient died in January 2010.

\section{Case 4}

This 58-year-old female patient with metastatic rectal cancer and neuropathic pain (DN4 score of 8) was unresponsive to intrathecal morphine $8 \mathrm{mg} /$ day (VAS score of 8). She was also receiving pregabalin $300 \mathrm{mg}$ every $12 \mathrm{~h}$, amitriptyline $50 \mathrm{mg}$ every $24 \mathrm{~h}$, and transdermal fentanyl $200 \mu \mathrm{g} / \mathrm{h} /$ day. Intrathecal ziconotide $0.6 \mu \mathrm{g} /$ day was added to therapy in March 2010. The patient's VAS score improved $50 \%$ from 8 at baseline to 4 , but ziconotide was discontinued after 3.5 months because the patient developed a neuropsychiatric disturbance that was considered to be related to treatment. At the end of treatment, the patient was receiving ziconotide $6 \mu \mathrm{g} / \mathrm{day}$. Intrathecal morphine was discontinued during the 3.5-month treatment period.

\section{Case 5}

This 63-year-old male patient with locally advanced colon cancer and neuropathic pain (DN4 score of four) was unresponsive to intrathecal morphine $9 \mathrm{mg}$ /day (VAS score of 8). He was also receiving gabapentin $1200 \mathrm{mg}$ every $8 \mathrm{~h}$, amitriptyline $50 \mathrm{mg}$ every $24 \mathrm{~h}$, and transdermal fentanyl $250 \mu \mathrm{g} / \mathrm{h} /$ day. Intrathecal ziconotide $1.0 \mu \mathrm{g} /$ day was added to therapy in August 2010. There was a two-point improvement in VAS score, but ziconotide was discontinued after 2 months of treatment (final ziconotide dose $5 \mu \mathrm{g} / \mathrm{day}+$ morphine $6 \mathrm{mg} /$ day) due to confusion and delirium that was considered to be related to treatment. The patient then returned to intrathecal treatment with morphine. Due to continued lack of pain control at high doses of intrathecal morphine 
and poor tolerance of ziconotide, intrathecal treatment with fentanyl was initiated. As effective pain relief was not achieved after reaching doses of fentanyl $1500 \mu \mathrm{g} /$ day (VAS score of 8), it was decided that treatment with intrathecal ziconotide should be reinitiated. Ziconotide was started at $0.7 \mu \mathrm{g}$ and was titrated to a final dose of $4 \mu \mathrm{g}$, at which time the patient was also receiving intrathecal fentanyl $1350 \mu \mathrm{g} /$ day. The patient died in August 2012, 6 months after improvement of pain control was achieved with intrathecal ziconotide and fentanyl (final VAS score of 6) without adverse events requiring discontinuation of the ziconotide infusion.

\section{Case 6}

This 57-year-old male patient with metastatic lung cancer had a DN4 score of 2, indicating that he had nociceptive rather than neuropathic pain. He was unresponsive to intrathecal morphine $11 \mathrm{mg} /$ day, had a VAS score of 9, and was also receiving oral pregabalin $300 \mathrm{mg}$ every $12 \mathrm{~h}$, amitriptyline $50 \mathrm{mg}$ every $24 \mathrm{~h}$, and oxycodone/naloxone controlled release $80 / 40 \mathrm{mg}$ every $12 \mathrm{~h}$. Intrathecal ziconotide was added to therapy at a starting dose of $0.5 \mu \mathrm{g} /$ day. The patient's VAS score improved $>50 \%$ from 9 at baseline to 4 , but ziconotide was discontinued after 2 months (final ziconotide dose $3.5 \mu \mathrm{g} /$ day + morphine $11 \mathrm{mg} /$ day) because the patient developed confusion that was considered to be related to treatment.

\section{Case 7}

This 59-year-old male patient with metastatic prostate cancer had a DN4 score of three, indicating that his pain was not primarily of neuropathic origin. He had a VAS score of 8 during intrathecal therapy with morphine $12 \mathrm{mg} /$ day. He was also receiving oral gabapentin $900 \mathrm{mg}$ every $8 \mathrm{~h}$, duloxetine $60 \mathrm{mg}$ every $24 \mathrm{~h}$, and morphine extended-release $100 \mathrm{mg}$ every $12 \mathrm{~h}$. The patient began intrathecal ziconotide at a starting dose of $0.5 \mu \mathrm{g} /$ day, but treatment was discontinued at 15 days (final ziconotide dose $1 \mu \mathrm{g} /$ day + morphine $12 \mathrm{mg} /$ day) because of adverse events (neurological and gastrointestinal disorders) that were considered to be treatment related. Final VAS score was 6 .

\section{Case 8}

This 71-year-old male patient with metastatic laryngeal cancer had DN4 score of three. He had a VAS score of 8 during therapy with intrathecal morphine $15 \mathrm{mg} /$ day. He was also receiving pregabalin $150 \mathrm{mg}$ every $12 \mathrm{~h}$, amitriptyline $25 \mathrm{mg}$ every $24 \mathrm{~h}$, and oxycodone/naloxone controlled release $80 / 40 \mathrm{mg}$ every $12 \mathrm{~h}$. Intrathecal ziconotide was started at a dose of $0.5 \mu \mathrm{g} /$ day in July 2012, and the patient was continuing treatment 1.2 months later with no reported adverse events. At his last assessment, the patient was receiving intrathecal ziconotide $1 \mu \mathrm{g} /$ day and morphine $15 \mathrm{mg} /$ day, and he had a $62.5 \%$ in reduction in pain intensity (VAS score of three).

\section{DISCUSSION}

The current case series suggests that addition of intrathecal ziconotide to intrathecal morphine therapy is a successful treatment strategy in patients with cancer pain, including neuropathic pain, refractory to high doses of intrathecal morphine alone. Combination therapy allowed rapid control of pain in our 
series of eight patients, as demonstrated by a reduction in pain intensity as soon as three to five days after the start of intrathecal ziconotide. All eight patients, five of whom had confirmed neuropathic pain, had a substantial reduction in pain intensity of $\geq 25 \%$. Two of three patients with a $\geq 50 \%$ reduction in pain intensity had DN4 scores $<4$, indicating that their pain was not primarily of neuropathic origin, and the third patient experienced effective relief of intense morphine-refractory neuropathic pain.

To our knowledge, there are no other published reports of the efficacy of an intrathecal combination of ziconotide and morphine in cancer patients with severe neuropathic pain refractory to high doses of intrathecal morphine. Two studies have demonstrated the efficacy of intrathecal combination therapy with ziconotide and morphine in reducing pain that was inadequately controlled by either intrathecal morphine or ziconotide alone in patients with chronic non-cancer pain $[22,25]$. More recently, intrathecal combination therapy with ziconotide and morphine was shown to be a successful treatment strategy in two studies of patients with cancer pain refractory to high doses of oral opioids $[15,16]$. However, one of these studies involved patients primarily with nociceptive pain from bone metastases [15], and in the other study results were reported only for the study population as a whole, not specifically for patients with neuropathic pain [16]. Our case series therefore represents an important addition to the small body of literature documenting the efficacy of an intrathecal combination of ziconotide and morphine in cancer patients with severe opioid-refractory pain.

In addition to recommending ziconotide or morphine alone as a first-line intrathecal treatment option, the PACC considers the combination of morphine plus bupivacaine an option for first-line intrathecal therapy in neuropathic pain [10]. There is a lack of data on the use of ziconotide in combination with other drugs [16]. However, as per the clinical practice in our pain unit, there is sound rationale for adding ziconotide to support the effects of intrathecal morphine as part of a multimodal intrathecal analgesia protocol [16, 22]. The PACC algorithms were created to help guide clinicians in the safe and effective use of intrathecal therapy, but physicians should use their own best clinical judgment in making treatment decisions for their patients [10]. Our case series helps to demonstrate the effectiveness of intrathecal combination therapy with ziconotide and morphine in cancer patients with neuropathic pain refractory to first-line intrathecal morphine-based therapy in clinical practice. With respect to its safety profile, ziconotide has a narrow therapeutic window, which requires careful titration to determine the lowest possible dose that is therapeutic and sufficiently well tolerated. A high starting dose and/or rapid dose titration can result in adverse effects, including psychiatric abnormalities [12]. These events frequently require discontinuation of ziconotide and are more likely associated with rapid titration than with the final dose achieved. Current PACC recommendations for intrathecal ziconotide treatment highlight the benefits of a slow titration plan to minimize the risk of adverse events [10]. To reduce the risk of serious adverse events, we employ a very low starting dosage and a slow titration of intrathecal ziconotide. However, it is necessary to remember that we are dealing with patients with relatively short-life expectancies, intense and frequently increasing pain, and are under significant social pressure for the rapid control of pain. For all these reasons, we are often 
required to perform rapid titration of ziconotide, with all the consequences that it implies. In the patients documented in this case series, treatment with ziconotide was initiated at $0.5-1.0 \mu \mathrm{g} /$ day (Table 2), with mean increases of $0.5 \mu$ g every 4-7 days, while morphine dose remained stable or was reduced. Four of the eight patients discontinued intrathecal ziconotide because of psychological/ neurological adverse events. One of these patients was subsequently able to successfully return to intrathecal therapy with ziconotide. Ziconotide-related adverse events have previously been reported with low doses of ziconotide [16], and one of our patients discontinued ziconotide because of adverse events when receiving a very low $1 \mu \mathrm{g} /$ day dose. The other adverse events occurred in patients receiving ziconotide 3.5-6 $\mu \mathrm{g} / \mathrm{day}$. The maximum final ziconotide dose was $10 \mu \mathrm{g} /$ day. This dose was well tolerated with no reported adverse events.

\section{CONCLUSIONS}

The use of combined intrathecal ziconotide and morphine, together with the practice of slow ziconotide titration, promotes successful pain management in cancer patients with severe refractory neuropathic pain. Although ziconotide can be used as a first-line intrathecal treatment option, on the basis of our clinical experience, we recommend adding ziconotide to intrathecal opioid-based therapy in cancer patients with neuropathic pain inadequately controlled by intrathecal morphine alone.

\section{ACKNOWLEDGMENTS}

The article processing charges for this publication were funded by Eisai, Spain. The authors would like to thank Simone Boniface and Joanne Dalton of Springer Healthcare Communications, who provided editorial assistance and styling prior to submission. This assistance was funded by Eisai, Spain. All named authors meet the International Committee of Medical Journal Editors (ICMJE) criteria for authorship for this manuscript, take responsibility for the integrity of the work as a whole, and have given final approval to the version to be published.

Disclosures. Ana Bella de la Calle Gil has no other conflict of interest to declare than editorial assistance funding from Eisai. Isaac Peña Vergara has no other conflict of interest to declare than editorial assistance funding from Eisai. María Auxiliadora Cormane Bornacelly has no other conflict of interest to declare than editorial assistance funding from Eisai. Antonio Pajuelo Gallego has no other conflict of interest to declare than editorial assistance funding from Eisai.

Compliance with ethics guidelines. All procedures followed were in accordance with the ethical standards of the responsible committee on human experimentation (institutional and national) and with the Helsinki Declaration of 1964 , as revised in 2013. Informed consent was obtained from all patients included in the study.

Open Access. This article is distributed under the terms of the Creative Commons AttributionNonCommercial 4.0 International License (http://creativecommons.org/licenses/by-nc/4. $0 /$ ), which permits any noncommercial use, distribution, and reproduction in any medium, provided you give appropriate credit to the original author(s) and the source, provide a link to the Creative Commons license, and indicate if changes were made. 


\section{REFERENCES}

1. Cleeland CS, Gonin R, Hatfield AK, et al. Pain and its treatment in outpatients with metastatic cancer. NEJM. 1994;330(9):592-6.

2. Grond S, Zech D, Diefenbach C, Bischoff A. Prevalence and pattern of symptoms in patients with cancer pain: a prospective evaluation of 1635 cancer patients referred to a pain clinic. J Pain Symptom Manage. 1994;9(6):372-82.

3. van den Beuken-van Everdingen $\mathrm{MH}$, de Rijke JM, Kessels AG, Schouten HC, van Kleef M, Patijn J. Prevalence of pain in patients with cancer: a systematic review of the past 40 years. Ann Oncol. 2007;18((9):1437-49.

4. Zhukovsky DS, Gorowski E, Hausdorff J, Napolitano B, Lesser M. Unmet analgesic needs in cancer patients. J Pain Symptom Manage. 1995;10(2):113-9.

5. Serlin RC, Mendoza TR, Nakamura Y, Edwards KR, Cleeland CS. When is cancer pain mild, moderate or severe? Grading pain severity by its interference with function. Pain. 1995;61(2):277-84.

6. Deandrea S, Montanari M, Moja L, Apolone G. Prevalence of undertreatment in cancer pain. A review of published literature. Ann Oncol. 2008;19(12):1985-91.

7. Raphael J, Ahmedzai S, Hester J, et al. Cancer pain: part 1: pathophysiology; oncological, pharmacological, and psychological treatments: a perspective from the British Pain Society endorsed by the UK Association of Palliative Medicine and the Royal College of General Practitioners. Pain Med. 2010;11(5):742-64.

8. Bennett MI, Rayment C, Hjermstad M, Aass N, Caraceni A, Kaasa S. Prevalence and aetiology of neuropathic pain in cancer patients: a systematic review. Pain. 2012;153(2):359-65.

9. Rayment C, Hjermstad MJ, Aass N, et al. Neuropathic cancer pain: prevalence, severity, analgesics and impact from the European Palliative Care Research Collaborative-Computerised Symptom Assessment study. Palliat Med. 2013;27(8):714-21.

10. Deer TR, Prager J, Levy R, et al. Polyanalgesic Consensus Conference 2012: recommendations for the management of pain by intrathecal (intraspinal) drug delivery: report of an interdisciplinary expert panel. Neuromodul J Int Neuromodul Soc. 2012;15(5):436-64.

11. The British Pain Society in consultation with the Association for Palliative Medicine and the Society of British Neurological Surgeons. Intrathecal drug delivery for the management of pain and spasticity in adults; recommendations for best clinical practice. ISBN 978-0-9551546-3-8. London: The British Pain Society; 2008.

12. Saulino M, Kim PS, Shaw E. Practical considerations and patient selection for intrathecal drug delivery in the management of chronic pain. J Pain Res. 2014;7:627-38.

13. Hassenbusch SJ, Portenoy RK, Cousins $\mathrm{M}$, et al. Polyanalgesic Consensus Conference 2003: an update on the management of pain by intraspinal drug delivery-report of an expert panel. J Pain Symptom Manage. 2004;27(6):540-63.

14. Elan. Elan receives approval from the European Commission to market PRIALT ${ }^{\mathrm{TM}}$ (100 micrograms/ $\mathrm{Ml}$ solution for infusion) for severe chronic pain. 22 February 2005 (online media release). http:// newsroom.elan.com/phoenix.zhtml?c=88326\&p= irol-newsArticle\&ID=677119\&highlight. Accessed Dec 11, 2012.

15. Alicino I, Giglio M, Manca F, Bruno F, Puntillo F. Intrathecal combination of ziconotide and morphine for refractory cancer pain: a rapidly acting and effective choice. Pain. 2012;153(1):245-9.

16. Dupoiron D, Bore F, Lefebvre-Kuntz D, et al. Ziconotide adverse events in patients with cancer pain: a multicenter observational study of a slow titration, multidrug protocol. Pain Physician. 2012;15(5):395-403.

17. Lux EA. Case report: successful treatment of a patient with trigeminal neuropathy using ziconotide. Anesth Analg. 2010;110(4):1195-7.

18. Rauck RL, Wallace MS, Leong MS, et al. A randomized, double-blind, placebo-controlled study of intrathecal ziconotide in adults with severe chronic pain. J Pain Symptom Manage. 2006;31(5):393-406.

19. Schmidtko A, Lotsch J, Freynhagen R, Geisslinger G. Ziconotide for treatment of severe chronic pain. Lancet. 2010;375(9725):1569-77.

20. Shields D, Montenegro R, Ragusa M. Chemical stability of admixtures combining ziconotide with morphine or hydromorphone during simul ated intrathecal administration. Neuromodulation. 2005;8(4):257-63.

21. Staats PS, Yearwood T, Charapata SG, et al. Intrathecal ziconotide in the treatment of refractory pain in patients with cancer or AIDS: a randomized controlled trial. JAMA. 2004;291(1):63-70. 
22. Wallace MS, Kosek PS, Staats P, Fisher R, Schultz DM, Leong M. Phase II, open-label, multicenter study of combined intrathecal morphine and ziconotide: addition of ziconotide in patients receiving intrathecal morphine for severe chronic pain. Pain Med. 2008;9(3):271-81.

23. Wallace MS, Rauck RL, Deer T. Ziconotide combination intrathecal therapy: rationale and evidence. Clin J Pain. 2010;26(7):635-44.

24. Perez C, Galvez R, Huelbes S, et al. Validity and reliability of the Spanish version of the DN4
(Douleur Neuropathique 4 questions) questionnaire for differential diagnosis of pain syndromes associated to a neuropathic or somatic component. Health Qual Life Outcomes. 2007;5:66.

25. Webster LR, Fakata KL, Charapata S, Fisher R, MineHart M. Open-label, multicenter study of combined intrathecal morphine and ziconotide: addition of morphine in patients receiving ziconotide for severe chronic pain. Pain Med. 2008;9(3):282-90. 